\title{
Prediction of Density of Binary Mixtures of Ionic Liquids with Alcohols \\ [Methanol/Ethanol/1-Propanol] using Artificial Neural Network
}

\author{
Karen Faith P. Ornedo - Ramos ${ }^{1}$ \\ Carla Angela M. Muriel ${ }^{1}$ \\ Adonis P. Adornado ${ }^{1}$ \\ Allan N. Soriano ${ }^{1}$ \\ Vergel C. Bungay ${ }^{*} 2$ \\ ${ }^{1}$ School of Chemical Engineering and Chemistry, Mapúa Institute of Technology, Manila \\ ${ }^{2}$ Chemical Engineering Department, De La Salle University, Manila \\ *e-mail:vergel.bungay@dlsu.edu.ph
}

Ionic liquids demonstrated successful potential applications in the industry most specifically as the new generation of solvents for catalysis and synthesis in chemical processes, thus knowledge of their physico-chemical properties is of great advantage. The present work presents a mathematical correlation that predicts density of binary mixtures of ionic liquids with various alcohols (ethanol/methanol/1-propanol). The artificial neural network algorithm was used to predict these properties based on the variations in temperature, mole fraction, number of carbon atoms in the cation, number of atoms in the anion, number of hydrogen atoms in the anion and number of carbon atoms in the alcohol. The data used for the calculations were taken from ILThermo Database. Total experimental data points of 1946 for the considered binaries were used to train the algorithm and to test the network obtained. The best neural network architecture determined was found to be 6-6-10-1 with a mean absolute error of 48.74 $\mathrm{kg} / \mathrm{m}^{3}$. The resulting correlation satisfactorily represents the considered binary systems and can be used accurately for solvent related calculations requiring properties of these systems.

Keywords: artificial neural network; ionic liquid; density; ethanol; methanol; propanol

\section{INTRODUCTION}

lonic liquids (ILs) play a significant role in the development of industrial chemistry and chemical technology as novel solvents which belong to the class of molten salts at room temperature (Gardas and Coutinho, 2009). ILs exhibit desirable properties such as negligible vapor pressure, non-flammability, large range of densities and viscosities, high potential for recycling, and highly solvating capacity for 
34 Prediction of Density of Binary Mixtures of Ionic Liquids with Alcohols (Methanol/Ethanol/1Propanol) using Artificial Neural Network

organic, inorganic and organometallic compounds. They are commonly known as the "green solvents" in industrial applications. The knowledge of viscosity, density and refractive index of aqueous ionic liquids solutions at various temperatures are required in both physical chemistry and chemical engineering calculations involving fluid flow, heat and mass transfer (Giro et al., 2003).

Diverse researches have been conducted for the potential applications of these ILs. They became significant solvents for chemical synthesis and catalysis, gasliquid absorption, liquid membrane separations, fuel and solar cells, nanomaterial technologies, preparation of polymer-gel catalytic membranes and generation of high conductivity materials (Gardas and Coutinho, 2008). Such applications lead to the development of thermodynamic models for computing the thermo-physical properties of ionic liquids like COSMO-RS which are now widelyused and efficient tools for the prediction of properties of ionic liquids (Diedenhofen and Klamt, 2010). As assessed by the previous studies, prediction of physical properties can be made possible by varying only one or two parameters such as temperature and pressure, disregarding the effect of each composition of the compounds in the binary system (Liu et al., 2008). Hydroxyl ammonium ionic liquids mixed with organic solvents boost its absorption capacity for $\mathrm{CO}_{2}$. In actual use, physico - chemical properties of hydroxyl ammonium ionic liquids with organic solvent mixtures are extremely important. Density and viscosity contributes of great importance in both practical and theoretical viewpoint. Although applications of ionic liquids are well known, detailed knowledge regarding the thermodynamic behavior of mixtures of ionic liquids with organic solvents has not received particularly large share of the literature on ionic liquid studies and is still limited (Kurnia et al., 2010).

A need for further development of these studies must be made to develop more accurate and efficient thermodynamic modeling in computing such properties, in conjunction with the fast growing number of binary ionic liquids with organic solvents. Predictive computing is one way of evaluating these thermo-physical properties and be able to generate model that predicts such physical property of binary ionic liquid solutions from various sources of data which were generally acquired from previous experiments through the use of some algorithm such as Artificial Neural Network (ANN). The ANN algorithm has been used for several applications, e.g. electronics, financial institutions, etc. but limited use of such algorithm has been made for chemical engineering applications.

The study aimed to develop a specific model that predicts the physical property, i.e., density of binary ionic liquid solutions containing methanol, ethanol, and 1propanol. Specifically, it aimed to optimize the best neural architecture for ANN computation; to determine the empirical parameters for the optimized ANN model; and to predict the density from the obtained parameters. 


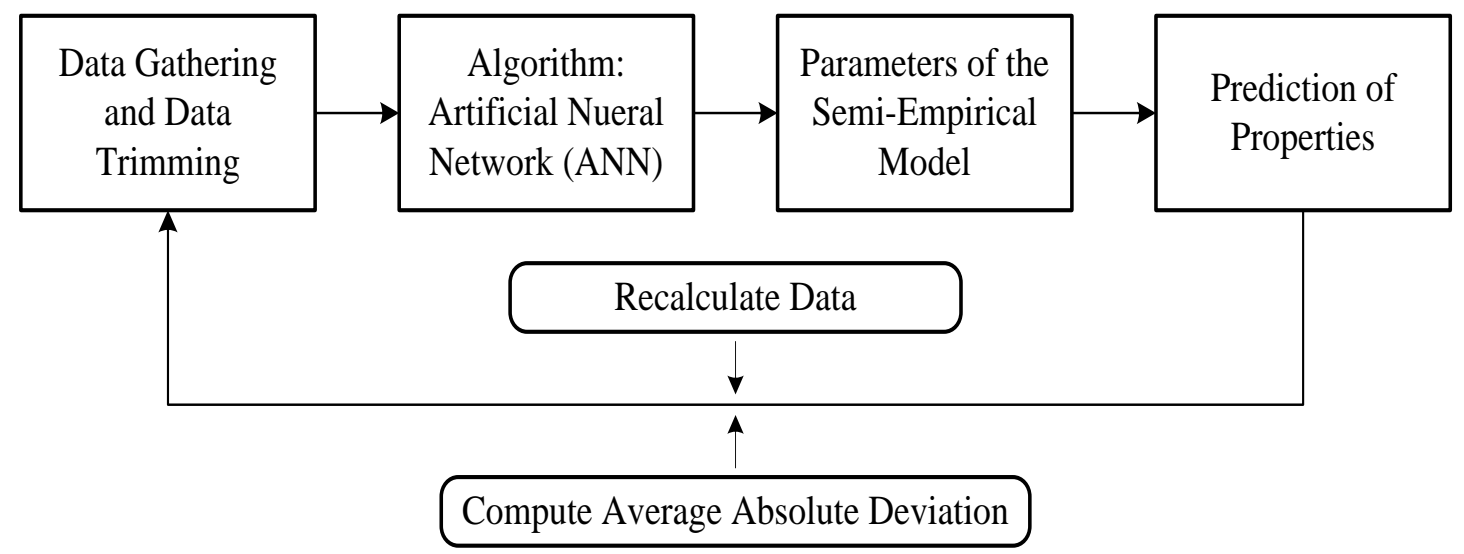

Fig. 1: Conceptual Framework

\section{METHODS}

Figure 1 presented the overall flow of process for the prediction of the considered properties. The details of each step were briefly discussed as follows:

\section{Data gathering and data trimming}

The present study is purely computational and the experimental data used for the calculations were taken from NIST Database, ILThermo. The complete details of the studied ionic liquids are included in the Appendix. A total of 6144 experimental data points for density were gathered. Tables 1 to 3 presented the details of these data, including the temperature range, pressure, mole fraction range, number of data points and the references for the respective binaries. Other information such as the number of atoms in the cation, number of $\mathrm{CH}_{3} \mathrm{R}$ in the cation, number of atoms in the anion and number of hydrogen atoms in the anion of the ILs was also collected.

All the data gathered were initially assessed by observing the corresponding trends, and then removing the data that seems to disagree with the overall trend. Accurate and reliable data results were considered. Data trimming was done by graphing all the data gathered from different references. Graphs of temperature versus property and mole fraction versus property were plotted. These graphs formed smooth curves. Points that were observed to be far or out from the smooth curve were omitted or were trimmed. The trimmed data were compiled into one spread sheet in preparation for the utilization of the algorithm. For density calculations, the number of data points left after trimming was 1946. The detailed trimming process applied in the present study was adopted from previous works (Soriano et al., 2010; 2014).

\section{Artificial neural network (ANN) algorithm}

The ANN model used for the algorithm is shown in Figure 2, which includes one 
36 Prediction of Density of Binary Mixtures of Ionic Liquids with Alcohols (Methanol/Ethanol/1Propanol) using Artificial Neural Network

Table 1. Density data for IL (1) + methanol (2) systems

\begin{tabular}{|c|c|c|c|c|c|}
\hline IL Code & $\begin{array}{c}\text { Temperature } \\
\text { range }(\mathrm{K})\end{array}$ & $\begin{array}{c}\text { Pressure } \\
(\mathrm{kPa})\end{array}$ & $\begin{array}{l}\text { Mole fraction } \\
\text { range }\end{array}$ & $\begin{array}{c}\text { Data } \\
\text { points }\end{array}$ & Reference \\
\hline C1A1 & $298.15-313.15$ & 101.325 & $0-1.0$ & 33 & Deenadayalu and Bhujrajh, 2008 \\
\hline \multirow[t]{2}{*}{ C1A6 } & 298.15-328.15 & 101.325 & $0-1.0$ & 39 & Gonzalez et al., 2007 \\
\hline & 283.15-333.15 & $100-35000$ & $0.06025-0.9522$ & 693 & Hofman et al., 2008 \\
\hline $\mathrm{C} 1 \mathrm{~A} 14$ & $278.15-318.15$ & 101.325 & $0.0511-0.9495$ & 65 & Vercher et al., 2007 \\
\hline \multirow[t]{2}{*}{ C2A8 } & 298.15 & 101.325 & $0.0802-0.934$ & 10 & Domanska et al., 2006 \\
\hline & 313.15-333.15 & $100-25000$ & $0.1212-0.9405$ & 315 & Goldon et al., 2007 \\
\hline C4A2 & 298.15-313.15 & 101.325 & $0.055-0.979$ & 48 & Bhujrajh and Deenadayalu, 2007 \\
\hline C4A4 & 298.15-318.15 & 101.325 & $0.00151-0.1109$ & 55 & Zafarani-Moattar and Shekaari, 2006b \\
\hline C4A5 & 293.15-318.15 & 101.325 & $0-0.518$ & 60 & Yang et al., 2010 \\
\hline \multirow[t]{3}{*}{ C4A7 } & 298.15-318.15 & 101.325 & $0-1.0$ & 60 & Zafarani-Moattar and Shekaari, 2005b \\
\hline & 298.15 & 101.325 & $0.000426-0.0193$ & 12 & Zafarani-Moattar and Shekaari, 2006a \\
\hline & 298.15-398.15 & 101.325 & $0-1.0$ & 360 & Abdulagatov et al., 2008b \\
\hline C4A8 & 298.15 & 101.325 & $0.0692-0.9493$ & 10 & Domanska et al., 2006 \\
\hline \multirow[t]{2}{*}{ C4A10 } & 298.15 & 101.325 & $0.092-0.9912$ & 10 & Domanska et al., 2006 \\
\hline & 298.15-298.15 & $290-40080$ & $0-0.9662$ & 315 & Abdulagatov et al., 2009 \\
\hline \multirow[t]{5}{*}{ C4A12 } & 298.15-318.15 & 101.325 & $0-1.0$ & 50 & Zafarani-Moattar and Shekaari, 2006b \\
\hline & 293.15-323.15 & 101.325 & $0-1.0$ & 112 & Iglesias-Otero et al., 2007 \\
\hline & 298.15-398.15 & 101.325 & $0.0898-0.9913$ & 315 & Abdulagatov et al., $2008 \mathrm{~b}$ \\
\hline & 298.15 & 101.325 & $0.00065-0.0202$ & 12 & Shekaari and Zafarani-Moattar, 2008 \\
\hline & 298.15 & 101.325 & $0.4417-0.9926$ & 11 & Stoppa et al., 2009 \\
\hline C4A13 & $298.15-328.15$ & 101.325 & $0-1.0$ & 52 & Domanska and Laskowska, 2009 \\
\hline \multirow[t]{2}{*}{ C5A12 } & 298.15-323.15 & 101.325 & $0-1.0$ & 39 & Heintz et al., 2002 \\
\hline & 298.15-318.15 & 101.325 & $0.0954-0.9461$ & 29 & Ortega et al., 2008 \\
\hline C7A2 & 298.15-315.15 & 101.325 & $0.110-0.909$ & 18 & Bhujrajh et al., 2007 \\
\hline C7A3 & 298.15 & 101.325 & $0.0654-0.9020$ & 10 & Andreatta et al., 2009b \\
\hline C7A5 & $298.15-328.15$ & 101.325 & $0-1.0$ & 45 & Gonzalez et al., 2006 \\
\hline C7A12 & 298.15 & 101.325 & $0.0951-0.9505$ & 13 & Arce et al., 2006a \\
\hline \multicolumn{2}{|c|}{ Total No. of Data Points } & & & 2791 & \\
\hline
\end{tabular}

input layer followed by hidden layer/s and an output layer being the last layer. The nodes in every layer were connected by weights $\left(w_{l^{\prime}-n}, w_{n-n^{\prime}}\right.$ or $\left.W_{n^{\prime}-Y}\right)$ as well as bias weights $\left(w_{b-n}, w_{b-n^{\prime}}\right.$ or $\left.W_{b-Y}\right)$ where the first subscript represents the source node and the second subscript represents the destination node.

In this study, aside from the temperature $(T)$ and mole fraction of the IL $(X)$, structure-related parameters such as number of carbon atoms in the cation (NCC), number of atoms in the anion (NA), number of hydrogen atoms in the anion $(\mathrm{NH})$ and number of carbon atoms in the alcohol (NCA) were also considered in the input layer as suggested by Viswanadhan et al. (1989) and Valderama et al. (2010). To simplify the model, a maximum number of two hidden layers and a maximum of 10 nodes per hidden layer were imposed and that there is only one expected output per neural network architecture, i.e., the density.

\section{Determination of the parameters of the model}

The mean absolute error (lowest), MAE (Eq. 1) was assigned as the basis for determining the best neural network 
Table 2. Density data for IL (1) + ethanol (2) systems

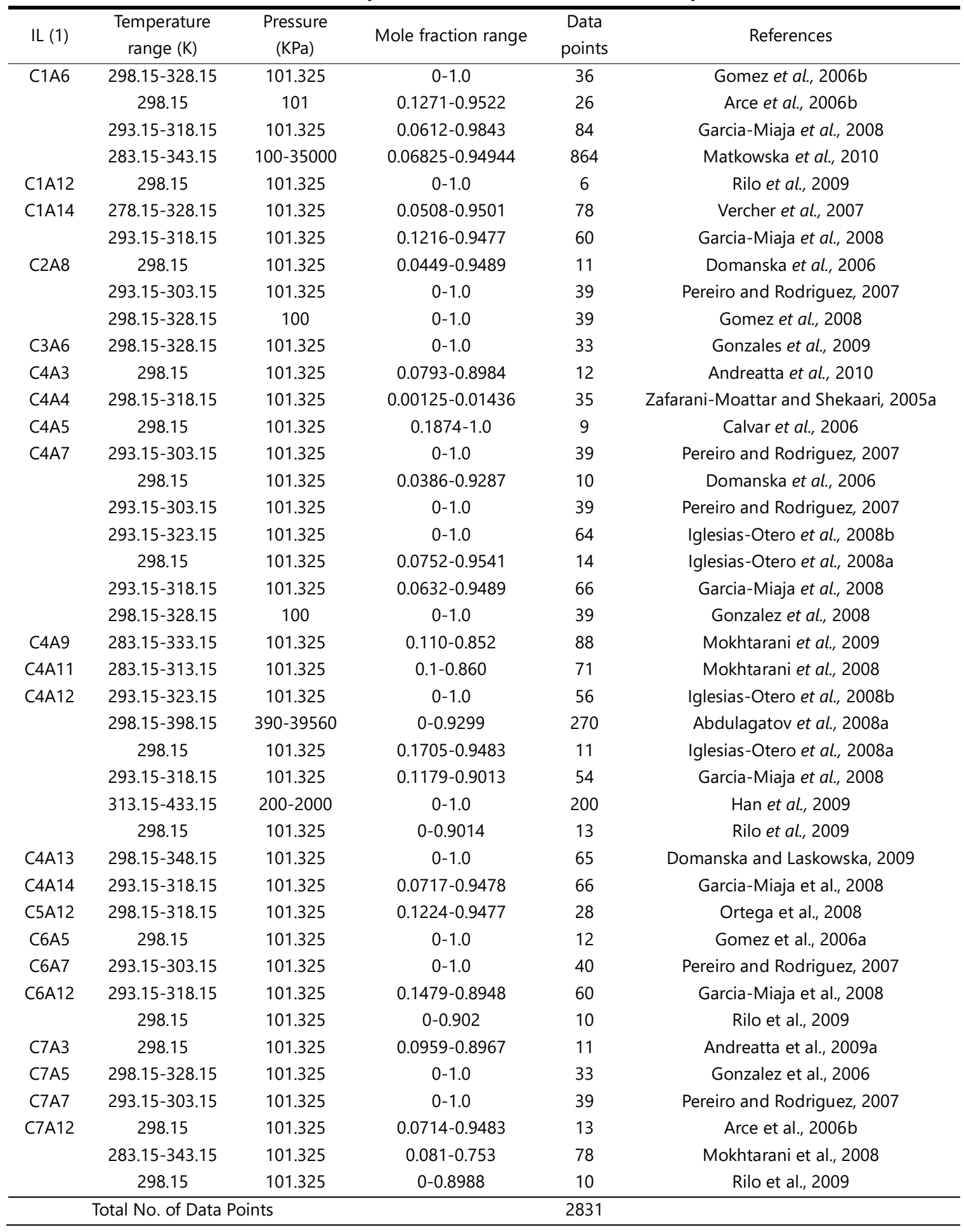

architecture. In Eq. (1), $L$ is the total number of data points, $Y_{l}$ is the predicted value and $E_{l}$ is the experimental or actual value. The flowchart for choosing the best neural network architecture is shown in
Figure 3.

$$
M A E=\frac{1}{L} \sum_{l=1}^{L}\left|Y_{l}-E_{l}\right|
$$


38 Prediction of Density of Binary Mixtures of Ionic Liquids with Alcohols (Methanol/Ethanol/1Propanol) using Artificial Neural Network

Table 3. Density data for IL (1) + 1-propanol (2) systems

\begin{tabular}{cccccc}
\hline IL Code & $\begin{array}{c}\text { Temperature } \\
\text { range }(\mathrm{K})\end{array}$ & $\begin{array}{c}\text { Pressure } \\
(\mathrm{kPa})\end{array}$ & $\begin{array}{c}\text { Mole fraction } \\
\text { range }\end{array}$ & $\begin{array}{c}\text { Data } \\
\text { points }\end{array}$ & Reference \\
\hline C1A6 & $298.15-328.15$ & 101.325 & $0-1.0$ & 33 & Gonzalez et al., 2007 \\
& 298.15 & 101.325 & $0-1.0$ & 14 & Domanska and Laskowska, 2008 \\
C1A14 & $278.15-338.15$ & 101.325 & $0.049-0.9499$ & 91 & Vercher et al., 2007 \\
C3A6 & $298.15-328.15$ & 101.325 & $0-1.0$ & 36 & Gonzalez et al., 2009 \\
C4A3 & 298 & 101.325 & $0-1.0$ & 11 & Wandschneider et al., 2008 \\
C4A9 & $293.15-333.15$ & 101.325 & $0.121-0.857$ & 88 & Mokhtarani et al., 2009 \\
C4A10 & $278.15-318.15$ & 101.325 & $0-0.07277$ & 30 & Orchilles et al., 2006 \\
C4A12 & 293.15 & 101.325 & $0-1.0$ & 72 & Huo et al., 2007 \\
C4A13 & $298.15-348.15$ & 101.325 & $0-1.0$ & 72 & Domanska et al., 2009 \\
C5A12 & $298.15-318.15$ & 101.325 & $0.0809-0.9846$ & 23 & Ortega et al., 2008 \\
C7A5 & $298.15-328.15$ & 101.325 & $0-1.0$ & 39 & Gonzalez et al., 2006 \\
C7A12 & 298.15 & 101.325 & $0.0082-0.9527$ & 13 & Arce et al., 2006a \\
\hline
\end{tabular}

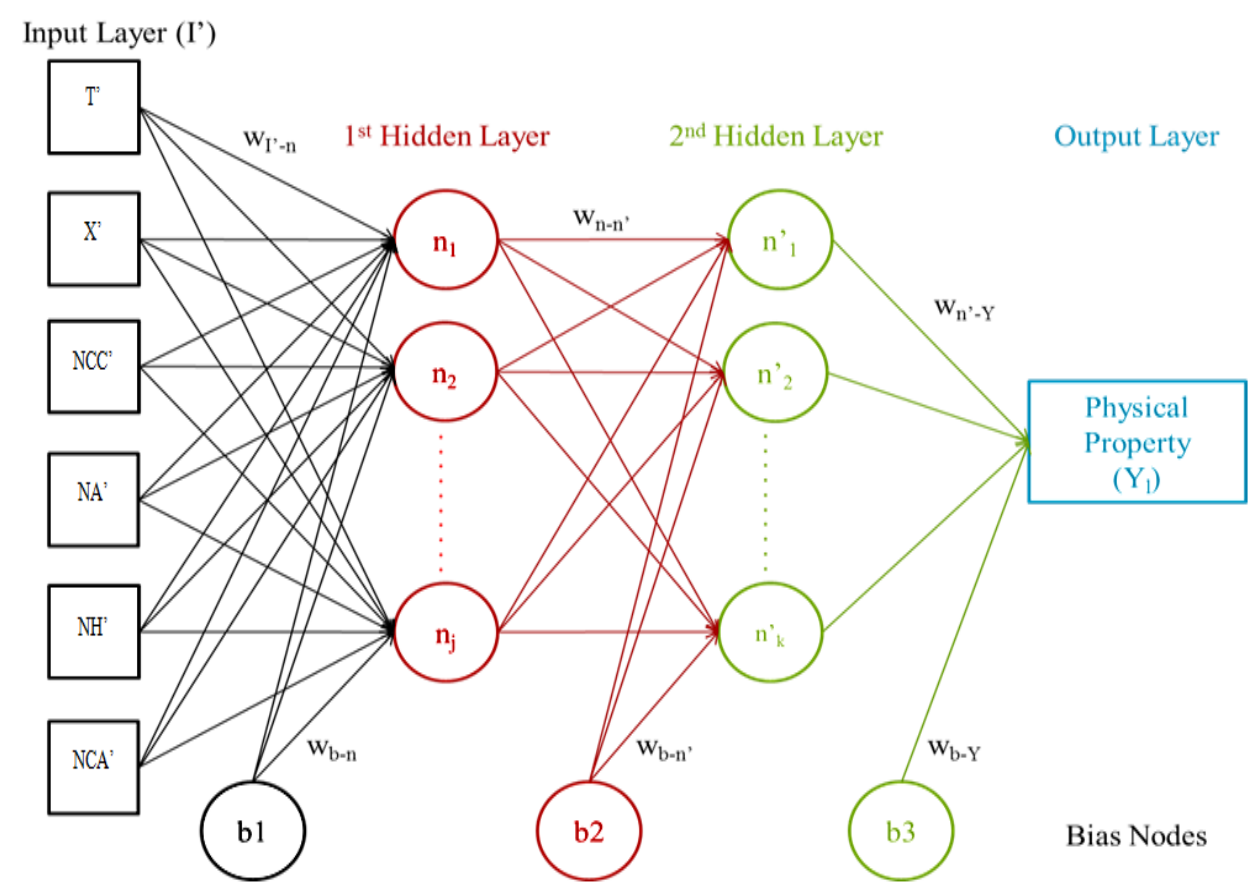

Fig. 2: ANN model with two hidden layers

The mathematical relationship between inputs, hidden layers and outputs is described by weights, bias weights, and transfer functions (Nguyen et al., 2007):

$n_{j}=f\left[\sum_{j=1}^{J}\left(I^{\prime}\right)\left(w_{l-n}+1\right)\left(w_{b-n}\right)\right]$

$$
\begin{aligned}
& n_{k}^{\prime}=f\left[\sum_{k=1}^{K^{\prime}}\left(n_{j}\right)\left(w_{n-n^{\prime}}+1\right)\left(w_{b-n^{\prime}}\right)\right] \\
& Y_{l}^{\prime}=f\left[\sum_{l=1}^{L^{\prime}}\left(n_{k}^{\prime}\right)\left(w_{n^{\prime}-Y}+1\right)\left(w_{b-Y}\right)\right]
\end{aligned}
$$

The transfer function used: 


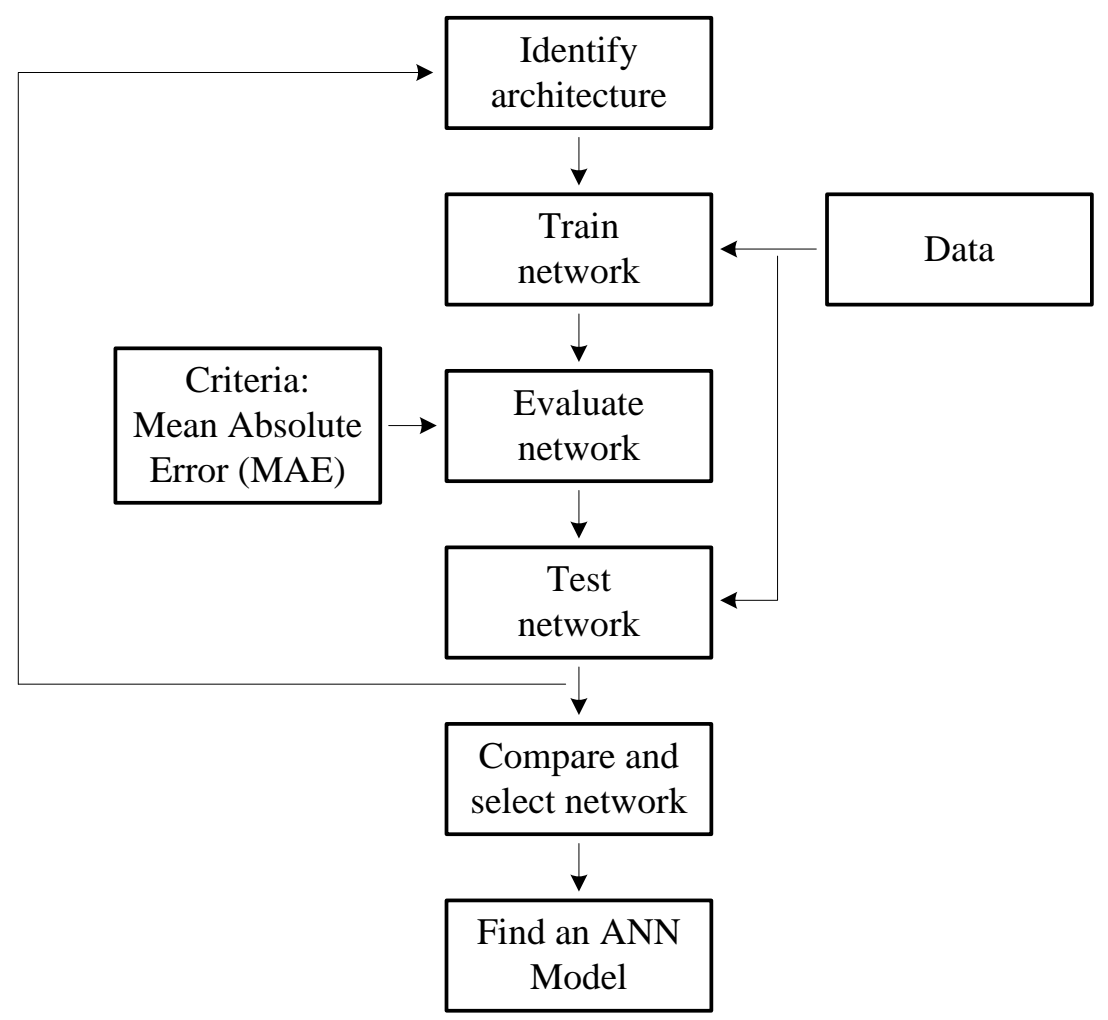

Fig. 3: Flowchart for determining neural network architecture

$f_{1}=\log \operatorname{sig}=\frac{1}{1+e^{-x}}$

The $I^{\prime}$ in Eq. (2) is a function of the input variables: $T, X, N C C, N A, N H$, and NCA and its corresponding slope, $m_{i}$ and intercept, $b_{i}$ and can be expressed as:

$$
I^{\prime}=m_{i} I+b_{i}
$$

The three termination criteria for training of ANN are the maximum number of epochs, training time and target mean square error, MSE (Eq. 7).

$\mathrm{MSE}=\frac{1}{L} \sum_{l=1}^{L}\left(Y_{l}-E_{l}\right)^{2}$

In the calculations, ninety percent $(90 \%)$ of the experimental data was used in training the neural network and remaining ten percent $(10 \%)$ of data was used in testing the generated model. After the training process, the parameters were obtained and the best neural network architecture was chosen.

\section{Prediction of properties}

All data points for density were recalculated using Eq. (9) where $Y_{l}$ is the predicted value and $Y_{l}^{\prime}$ is the output node and is a function of the determined weights, bias weights and the corresponding slope and intercept for the given set of data points (Eq. 4).

$Y_{l}^{\prime}=m_{l} Y_{l}+b_{l}$

$$
Y_{l}=\frac{Y^{\prime}{ }_{l}-b_{l}}{m_{l}}
$$


40 Prediction of Density of Binary Mixtures of Ionic Liquids with Alcohols (Methanol/Ethanol/1Propanol) using Artificial Neural Network

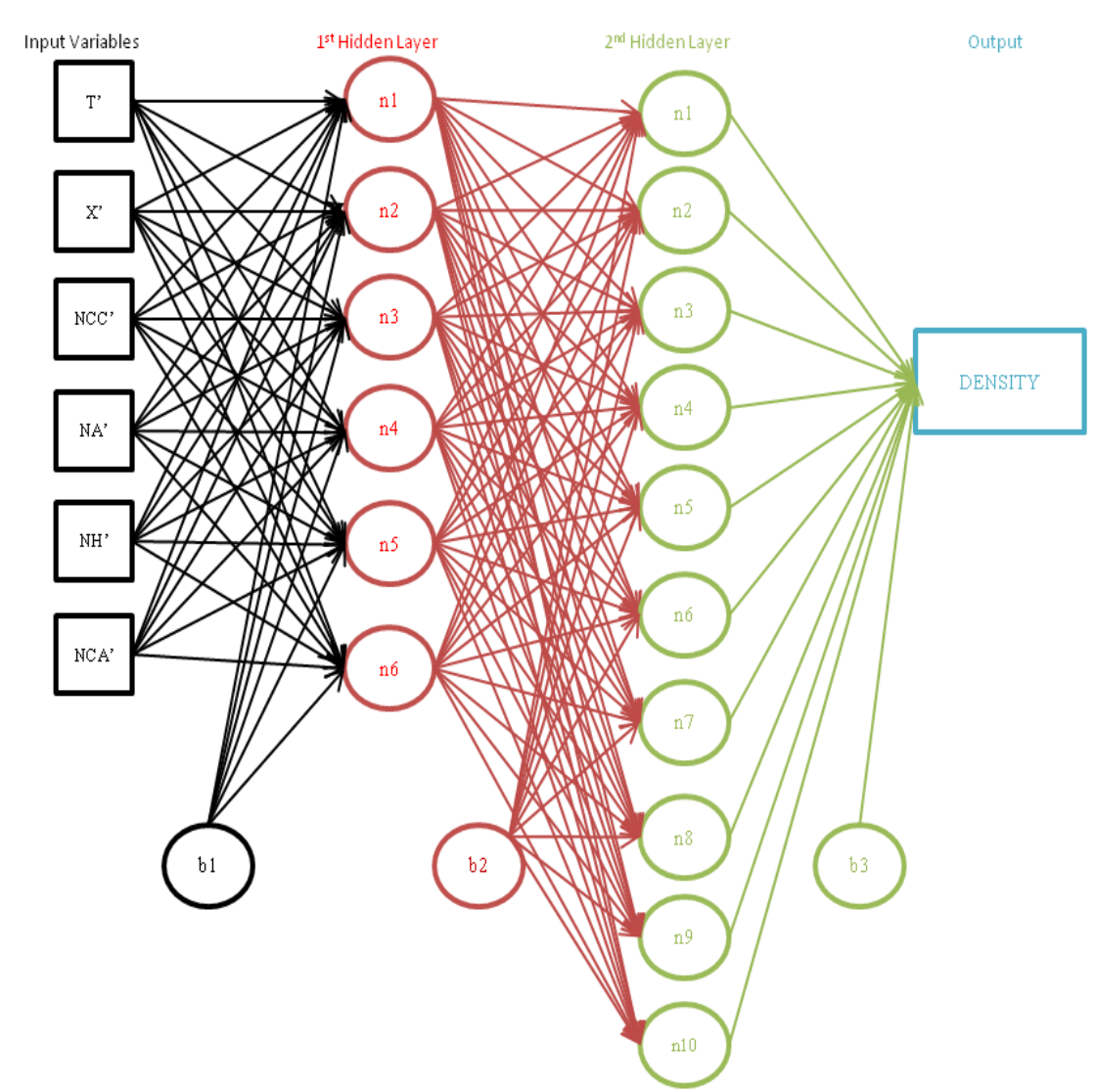

Fig. 4: Best neural network architecture for density calculations.

Finally, the mean absolute error was determined using Eq. (1). For the purpose of interpreting the result, the percentage error, as in Eq. (10) was also determined and the predicted and experimental values of the properties were classified and plotted based on the percentage error. Percentage error ranging from $0-1 \%$ was marked green, $1-5 \%$ was marked yellow and error more than $5 \%$ was marked red.

Percentage error $=\frac{\left|E_{l}-Y_{l}\right|}{E_{l}} \times 100 \%$

\section{RESULTS AND DISCUSSION}

There were 6144 data points collected for density which were obtained from various literatures as summarized by the
ILThermo Database. Out of the total data points, only 1946 trimmed binary IL data were used for the calculations, i.e., training the network and obtaining the optimum neural network parameters. These parameters were adjusted for different trial-and-error stage (epoch) until the best neural network architecture was determined.

Figure 4 shows the best neural network architecture in predicting density. This model is called 6-6-5-1 neural network architecture. This network architecture means that each weight from the input layer is being sent to the 6 nodes of the first hidden layer. Then each weight from the first hidden layer goes to the five nodes of the second hidden layer. The weights produced from the second hidden 
Karen Faith P. Ornedo - Ramos, Carla Angela M. Muriel, Adonis P. Adornado, Allan N. Soriano, 41 and Vergel C. Bungay

Table 4. Prediction of density of the considered IL (1) + methanol (2) systems

\begin{tabular}{|c|c|c|c|c|c|}
\hline IL Code & $\begin{array}{l}\text { Temperature } \\
\text { Range }(\mathrm{K})\end{array}$ & $\begin{array}{l}\text { Mole Fraction } \\
\text { Range }\end{array}$ & $\begin{array}{l}\text { Experimental Density } \\
\text { Range }\left(\mathrm{kg} / \mathrm{m}^{3}\right)\end{array}$ & $\begin{array}{c}\% \\
\text { Error }\end{array}$ & $\begin{array}{l}\text { No. of } \\
\text { Data Points }\end{array}$ \\
\hline $\mathrm{C} 1 \mathrm{~A} 1$ & $298.15-313.15$ & $0.0000-1.0000$ & 799.1-1391.0 & $10.28 \%$ & 12 \\
\hline $\mathrm{C} 1 \mathrm{~A} 6$ & $283.15-328.15$ & $0.0000-1.0000$ & $814.4-1200.3$ & $4.07 \%$ & 108 \\
\hline C1A8 & $298.15-333.15$ & $0.0595-0.8788$ & $888.2-1256.0$ & $3.91 \%$ & 50 \\
\hline $\mathrm{C} 4 \mathrm{~A} 2$ & 298.15-313.15 & $0.055-0.9790$ & 808.8-1101.5 & $9.49 \%$ & 48 \\
\hline C4A4 & $298.15-318.15$ & 0.00151-0.1109 & $846.5-953.0$ & $5.77 \%$ & 55 \\
\hline C4A5 & $293.15-318.15$ & $0.0000-0.5180$ & $845.1-1054.8$ & $6.05 \%$ & 60 \\
\hline C4A8 & 298.15 & $0.0692-0.9493$ & $875.0-1093.6$ & $7.11 \%$ & 10 \\
\hline C4A13 & $298.15-328.15$ & $0.0000-1.0000$ & $828.2-1106.5$ & $4.89 \%$ & 52 \\
\hline C7A2 & $298.15-315.15$ & $0.110-0.9090$ & $858.3-1042.4$ & $7.05 \%$ & 18 \\
\hline C7A3 & 298.15 & $0.0654-0.9020$ & $869.0-1070.0$ & $18.33 \%$ & 10 \\
\hline C7A5 & $298.15-328.15$ & $0.0000-1.0000$ & 840.8-1072.3 & $7.76 \%$ & 45 \\
\hline \multirow[t]{2}{*}{ C7A12 } & 298.15 & $0.0951-0.9505$ & $883.2-1066.8$ & $1.84 \%$ & 13 \\
\hline & & Total & & $6.04 \%$ & 481 \\
\hline
\end{tabular}

Table 5. Prediction of density of the considered IL (1) + ethanol (2) systems

\begin{tabular}{lccccc}
\hline IL Code & $\begin{array}{c}\text { Temperature } \\
\text { Range }(\mathrm{K})\end{array}$ & $\begin{array}{c}\text { Mole Fraction } \\
\text { Range }\end{array}$ & $\begin{array}{c}\text { Experimental Density } \\
\text { Range }\left(\mathrm{kg} / \mathrm{m}^{3}\right)\end{array}$ & $\begin{array}{c}\% \\
\text { Error }\end{array}$ & $\begin{array}{c}\text { No. of Data } \\
\text { Points }\end{array}$ \\
\hline C1A6 & $283.15-343.15$ & $0.0000-1.0000$ & $800.7-1256.7$ & $4.85 \%$ & 241 \\
C1A8 & $293.15-328.15$ & $0.0000-1.0000$ & $821.5-1281.7$ & $4.05 \%$ & 84 \\
C1A12 & 298.15 & $0.0714-0.9483$ & $881.3-1330.4$ & $13.50 \%$ & 13 \\
C1A14 & $278.15-328.15$ & $0.0508-0.9501$ & $844.7-1247.8$ & $3.78 \%$ & 138 \\
C3A6 & $298.15-328.15$ & $0.0000-1.0000$ & $808.7-1153.2$ & $4.72 \%$ & 33 \\
C4A3 & 298.15 & $0.0793-0.8984$ & $914.7-1242.5$ & $9.62 \%$ & 7 \\
C4A4 & $298.15-318.15$ & $0.0013-0.0144$ & $838.2-864.3$ & $8.00 \%$ & 35 \\
C4A5 & 298.15 & $0.1874-1.0000$ & $851.4-1080.4$ & $6.34 \%$ & 9 \\
C4A9 & $283.15-333.15$ & $0.1100-0.8520$ & $944.6-1105.0$ & $2.75 \%$ & 88 \\
C4A11 & $283.15-313.15$ & $0.1000-0.8600$ & $944.8-1094.5$ & $6.71 \%$ & 45 \\
C4A13 & $298.15-348.15$ & $0.0000-1.0000$ & $809.3-1117.1$ & $6.98 \%$ & 65 \\
C6A5 & 298.15 & $0.0000-1.0000$ & $854.7-1373.6$ & $3.27 \%$ & 6 \\
C6A7 & $293.15-303.15$ & $0.0000-1.0000$ & $823.3-1213.2$ & $3.74 \%$ & 40 \\
C6A12 & $293.15-318.15$ & $0.0000-0.9020$ & $908.5-1079.4$ & $2.87 \%$ & 70 \\
C7A3 & 298.15 & $0.0959-0.8967$ & $865.5-1068.7$ & $6.12 \%$ & 11 \\
C7A5 & $298.15-328.15$ & $0.0000-1.0000$ & $833.0-1072.5$ & $8.66 \%$ & 33 \\
C7A7 & $293.15-303.15$ & $0.0000-1.0000$ & $819.5-1071.7$ & $9.03 \%$ & 39 \\
\hline & & Total & & $5.18 \%$ & 957 \\
\hline
\end{tabular}

layer are called the output weights. The bias weights and the output bias weight also went to every node in the hidden layer. This best neural network architecture resulted to mean absolute error of 48.74 $\mathrm{kg} / \mathrm{m}^{3}$, having an average percentage error of $4.46 \%$, as specifically presented in Tables 4 to 6 . 
42 Prediction of Density of Binary Mixtures of Ionic Liquids with Alcohols (Methanol/Ethanol/1Propanol) using Artificial Neural Network

Table 6. Prediction of density of the considered IL (1) + 1-propanol (2) systems

\begin{tabular}{|c|c|c|c|c|c|}
\hline IL Code & $\begin{array}{l}\text { Temperature } \\
\text { Range }(\mathrm{K})\end{array}$ & $\begin{array}{l}\text { Mole Fraction } \\
\text { Range }\end{array}$ & $\begin{array}{l}\text { Experimental Density } \\
\text { Range }\left(\mathrm{kg} / \mathrm{m}^{3}\right)\end{array}$ & $\begin{array}{l}\% \\
\text { Error }\end{array}$ & $\begin{array}{l}\text { No. of } \\
\text { Data Points }\end{array}$ \\
\hline C1A6 & $298.15-328.15$ & $0.0000-1.0000$ & 791.0-1290.6 & $2.91 \%$ & 38 \\
\hline C1A14 & $278.15-338.15$ & 0.0490-0.9499 & $830.9-1382.6$ & $1.32 \%$ & 91 \\
\hline C3A6 & $298.15-328.15$ & $0.0000-1.0000$ & $788.4-1234.5$ & $0.99 \%$ & 36 \\
\hline C4A3 & 298 & $0.0000-1.0000$ & $802.5-1226.5$ & $3.33 \%$ & 6 \\
\hline C4A9 & 293.15-333.15 & $0.1210-0.8570$ & $882.1-1166.6$ & $1.78 \%$ & 88 \\
\hline C4A10 & $278.15-318.15$ & $0.0000-0.0728$ & 796.8-913.4 & $1.19 \%$ & 30 \\
\hline $\mathrm{C} 4 \mathrm{~A} 12$ & 293.15 & $0.0000-1.0000$ & $780.5-1173.0$ & $1.46 \%$ & 72 \\
\hline C4A13 & $298.15-348.15$ & $0.0000-1.0000$ & 776.7-1135.2 & $3.51 \%$ & 72 \\
\hline C5A12 & $298.15-318.15$ & $0.0809-0.9846$ & $821.5-1158.3$ & $0.76 \%$ & 23 \\
\hline C7A5 & $298.15-328.15$ & $0.0000-1.0000$ & 782.6-1029.1 & $1.46 \%$ & 39 \\
\hline \multirow[t]{2}{*}{ C7A12 } & 298.15 & $0.0082-0.9527$ & $853.0-1144.7$ & $4.62 \%$ & 13 \\
\hline & & Total & & $6.04 \%$ & 481 \\
\hline
\end{tabular}

The percentage errors for the prediction of density were ranging from $(1.84-18.33 \%)$, (2.75-13.50 \%), and $(0.76-4.62 \%)$ for binary IL system with methanol, ethanol, and 1-propanol, as presented in Tables 4,5 and 6, respectively. The calculation results showed that the binary system consisting of 1-methyl-3octylimidazolium bis [(trifluoromethyl) sulfonyl] imide (C7A3) and methanol with 10 data points led to the highest percentage error and the binary system of 1 - butyl - 4 - methylpyridinium tetrafluoroborate (C5A12) and 1-propanol having 23 data points has the lowest percentage error acquired. Such high percentage errors could be attributed to the inconsistency of experimental data which might be due to impurities of the substances or the inaccuracy of the instruments and measurement methods. Overall, the calculated percentage errors for density led to a good prediction as shown by an overall percentage error of $4.46 \%$ for a total of 1946 data points.
Tables 7 to 9 show the values of the weights and bias weights that resulted from applying the ANN algorithm in the prediction of density. These values are the result of the density property modeling which obtained the following best neural network architecture for the three alcohols which is 6-6-10-1. The simplified generated equation for the prediction of density is given in Eq. (11) which is a function of parameters $A_{1} B_{n^{\prime}}$ and $C_{n}$. Here, the parameter $C_{n}$ is a function of $T, X, N C C$, $N A$, NH, and NCA.

$$
\begin{aligned}
& \text { Predicted density }=\frac{1}{0.0012}\left(\frac{1}{1+e^{-A}}\right) \\
& -722.333 \\
& A=\sum_{n^{\prime}=1}^{5}\left[W_{b-Y}+W_{n^{\prime}-Y}\left(\frac{1}{1+e^{-B_{n^{\prime}}}}\right)\right] \\
& B_{n^{\prime}}=\sum_{n=1}^{6}\left[W_{b-n^{\prime}}+W_{n-n^{\prime}}\left(\frac{1}{1+e^{-C_{n}}}\right)\right]
\end{aligned}
$$


Table 7. Weights and bias weight for hidden layer 1

\begin{tabular}{cccccccc}
\hline $\mathrm{N}$ & $\mathrm{W}_{\mathrm{b}-\mathrm{n}}$ & $\mathrm{W}_{T-n}$ & $\mathrm{~W}_{X-n}$ & $\mathrm{~W}_{N C C-n}$ & $\mathrm{~W}_{\text {NA-n }}$ & $\mathrm{W}_{N H-n}$ & W NCA-n \\
\hline 1 & 0.7280 & -0.4674 & -0.8391 & -0.4261 & 5.5493 & -5.1527 & 0.3429 \\
2 & -0.3413 & -0.3135 & -0.4731 & -0.0355 & 0.1239 & 0.0522 & -0.6640 \\
3 & 0.7225 & 0.2206 & -3.2701 & -1.0472 & -1.1601 & -1.6074 & 1.1342 \\
4 & 2.6039 & -0.7382 & -1.3733 & 4.5201 & -3.7763 & 2.8212 & -0.1222 \\
5 & -1.2158 & 0.6865 & -10.8440 & -0.1471 & 2.0057 & -1.3101 & 0.2185 \\
6 & -0.0015 & -0.0328 & -2.2341 & 0.1008 & 0.6625 & 0.8402 & -0.0106 \\
\hline
\end{tabular}

Table 8. Weights and bias weight for hidden layer 2

\begin{tabular}{cccccccc}
\hline $\mathrm{n}^{\prime}$ & $W_{\mathrm{b}-\mathrm{n}^{\prime}}$ & $W_{1-\mathrm{n}^{\prime}}$ & $W_{2-\mathrm{n}^{\prime}}$ & $W_{3-\mathrm{n}^{\prime}}$ & $W_{4-\mathrm{n}^{\prime}}$ & $W_{5-\mathrm{n}^{\prime}}$ & $W_{6-\mathrm{n}^{\prime}}$ \\
\hline $1^{\prime}$ & -0.3911 & 0.0574 & -0.0163 & -0.0936 & -0.2325 & -0.1208 & 0.2883 \\
$2^{\prime}$ & 0.0983 & 0.9683 & 0.1982 & -0.8596 & -1.4788 & -1.8013 & -0.2031 \\
$3^{\prime}$ & -0.1527 & 0.5795 & -0.4707 & -0.2379 & -1.0287 & -0.8437 & -0.7145 \\
$4^{\prime}$ & 0.3239 & 0.9920 & -0.2450 & -0.7687 & -0.4106 & -1.6264 & -0.5324 \\
$5^{\prime}$ & -0.0699 & -0.8325 & 0.3289 & 0.6523 & 0.5428 & 0.9378 & 0.1908 \\
$6^{\prime}$ & -0.4978 & -1.3258 & -0.1224 & 0.4315 & 0.5872 & 1.7996 & 0.4355 \\
$7^{\prime}$ & -0.4388 & 0.2391 & 0.1011 & -0.2718 & -0.5748 & -0.1875 & 0.0062 \\
$8^{\prime}$ & -0.4745 & -1.1745 & -0.2377 & 0.5768 & 0.7125 & 1.5954 & -0.2249 \\
$9^{\prime}$ & -0.2672 & -0.6156 & 0.2156 & -0.0443 & 0.0146 & 1.2225 & 0.3799 \\
$10^{\prime}$ & -0.4644 & -0.1972 & -0.3677 & 0.3961 & 0.2437 & -0.3796 & -0.1892 \\
\hline
\end{tabular}

Table 9. Weights and bias weight for the output layer

\begin{tabular}{|c|c|c|c|c|c|}
\hline $\mathrm{Wb}-\mathrm{Y}$ & $\mathrm{W} 1^{\prime}-\mathrm{Y}$ & $\mathrm{W} 2^{\prime}-\mathrm{Y}$ & $\mathrm{W} 3^{\prime}-\mathrm{Y}$ & $\mathrm{W} 4^{\prime}-\mathrm{Y}$ & W5-Y \\
\hline 0.1331 & 0.1169 & 2.5970 & 1.4678 & 2.0121 & -1.5020 \\
\hline $\mathrm{W} 6 \cdot \mathrm{Y}$ & $\mathrm{W} 7 \cdot \mathrm{Y}$ & W 8 -Y & W'-Y & $\mathrm{W} 10^{\prime}-\mathrm{Y}$ & \\
\hline-2.2819 & 0.3867 & -1.9859 & -1.2140 & -0.0058 & \\
\hline
\end{tabular}

$$
\begin{aligned}
C_{n} & =w_{b-n}+0.0143 w_{T-n}(T-277.87) \\
& +w_{x-n} X+0.1429 w_{N C C-n}(N C C-5) \\
& +0.0345 w_{N A-n}(N A-1) \\
& +0.0588 w_{N H-n} N H \\
& +0.5 w_{N C A-n}(N C A-1)
\end{aligned}
$$

As shown in Figure 5, the best neural network architecture was able to predict the experimental values successfully where the predicted values of density were found to be in good agreement with the experimental data. Of the calculated density, $13.13 \%$ were within the percentage error range of $0-1 \%$ which was marked green in Figure 5, $51.21 \%$ were in the range of $1-5 \%$ which was marked yellow and $35.66 \%$ of the studied compounds have the percentage error higher than $5 \%$ which were marked red. Although the number of data points with 
44 Prediction of Density of Binary Mixtures of Ionic Liquids with Alcohols (Methanol/Ethanol/1Propanol) using Artificial Neural Network

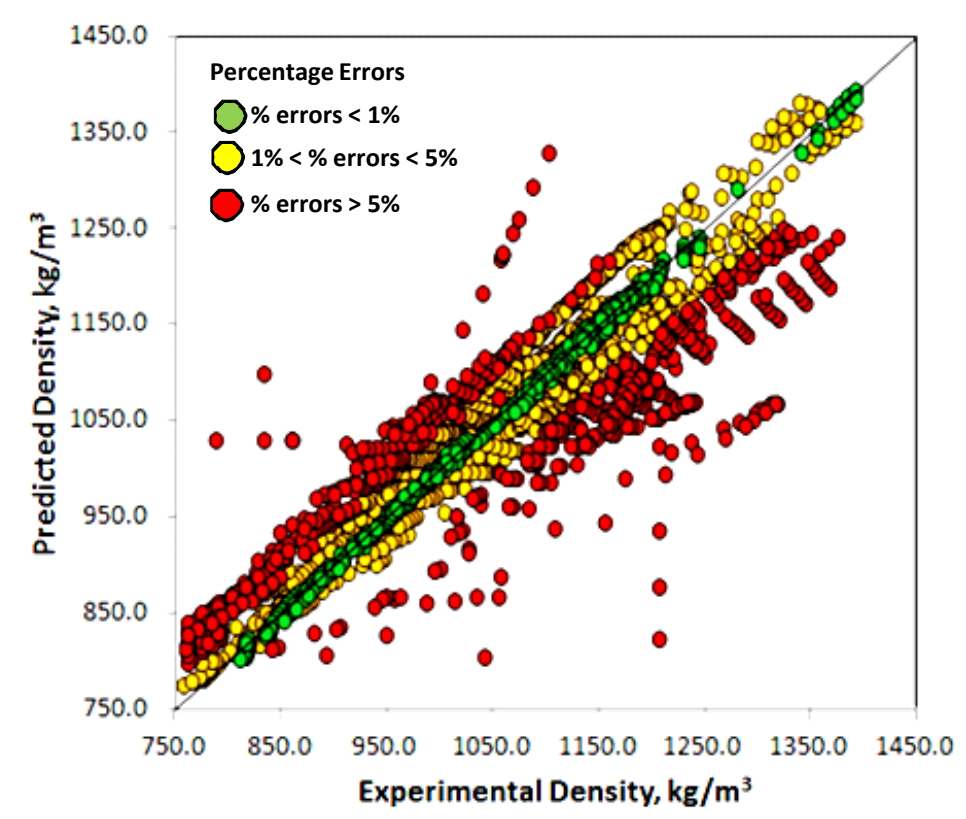

Fig.5: Predicted density versus experimental density

percentage error greater than $5 \%$ is high but compared to the combined percentage of acceptable error which amounts to $64.34 \%$, the model obtained using the 6-6-10-1 architecture can be deemed as acceptable.

\section{CONCLUSION}

Artificial neural network (ANN) can be utilized as an algorithm in designing a model that will help predict the density of binary mixture of ionic liquid solutions with various alcohols such as: ethanol, methanol and 1-propanol. Density data from ILThermo Database was utilized and the densities were predicted as functions of temperature, mole fraction, number of carbon group in the cation, number of atoms in the anion, number of hydrogen atoms in anion and the number of carbon atoms in the alcohol. Using ANN, the best neural network architecture acquired has six nodes in the first hidden layer and ten nodes in the second hidden layer, having a mean absolute error of $48.74 \mathrm{~kg} / \mathrm{m}^{3}$ and an average percentage error of $4.46 \%$. Among the considered binaries containing IL (1) + Alcohol (2), the binary system containing 1-propanol shows the lowest percentage error of $1.91 \%$ due to the consistency of the experimental data used for the modeling. Overall, there is a good agreement between the experimental density data with the predicted data using ANN. If no experimental data is available, the proposed model is a potential tool to estimate the density of binary ionic liquid solutions containing the alcohols methanol/ethanol/1-propanol.

\section{APPENDIX}

\begin{tabular}{llc}
$\begin{array}{l}\text { Cation } \\
\text { Name }\end{array}$ & Structure & $\begin{array}{c}\text { Cation } \\
\text { Code }\end{array}$ \\
\hline $\begin{array}{l}\text { 1-Ethyl-3- } \\
\text { methylimidaz } \\
\text { olium }\end{array}$ &
\end{tabular}




\begin{tabular}{|c|c|c|c|c|c|}
\hline & & & Anion & \multirow{2}{*}{ Structure } & \multirow{2}{*}{$\begin{array}{l}\text { Anion } \\
\text { Code }\end{array}$} \\
\hline Cation & \multirow{2}{*}{ Structure } & Cation & Name & & \\
\hline Name & & Code & Chloride & $\mathrm{Cl}^{-}$ & A5 \\
\hline $1,3-$ & & \multirow{3}{*}{$\mathrm{C} 2$} & \multirow{2}{*}{ Ethylsulfate } & & \multirow[t]{2}{*}{ A6 } \\
\hline Dimethylimid & & & & & \\
\hline azolium & & & \multirow{2}{*}{$\begin{array}{l}\text { Hexafluoro } \\
\text { phosphate }\end{array}$} & & \multirow[b]{2}{*}{ A7 } \\
\hline $1-$ & & \multirow{2}{*}{$\mathrm{C} 3$} & & & \\
\hline $\begin{array}{l}\text { Ethylpyridiniu } \\
\text { m }\end{array}$ & & & \multirow{2}{*}{$\begin{array}{l}\text { Methyl } \\
\text { sulfate }\end{array}$} & & \multirow{2}{*}{ A8 } \\
\hline 1-Butyl-3- & & \multirow[b]{2}{*}{ C4 } & & & \\
\hline $\begin{array}{l}\text { methylimidaz } \\
\text { olium }\end{array}$ & & & Nitrate & & A9 \\
\hline $\begin{array}{l}\text { 1-Butyl-4- } \\
\text { methylpyridin }\end{array}$ & & \multirow[t]{2}{*}{ C5 } & Octylsulfate & & A10 \\
\hline ium & & & \multirow[b]{2}{*}{ Perchlorate } & \multirow[b]{2}{*}{$\mathrm{o}=\mathrm{cl}=0$} & \multirow[b]{2}{*}{ A11 } \\
\hline $\begin{array}{l}\text { 1-Hexyl-3- } \\
\text { methylimidaz }\end{array}$ & & \multirow[t]{2}{*}{$\mathrm{C} 6$} & & & \\
\hline olium & & & \multirow{2}{*}{$\begin{array}{l}\text { Tetrafluorobo } \\
\text { rate }\end{array}$} & \multirow{2}{*}{$\left.\right|_{B} ^{F}-{ }_{F}$} & \multirow{2}{*}{$\mathrm{A} 12$} \\
\hline 1-Methyl-3- & & \multirow[t]{3}{*}{$C 7$} & & & \\
\hline octylimidazol & & & Thiocyanate & ${ }_{\mathrm{N}} \equiv \mathrm{C}^{-}$ & A13 \\
\hline Ium & & & Trifluoro & & \multirow{3}{*}{ A14 } \\
\hline Anion & \multirow{2}{*}{ Structure } & Anion & methanesulfo & $\mathrm{o}=\mathrm{s}=\mathrm{o}$ & \\
\hline Name & & Code & nate & - & \\
\hline
\end{tabular}

1,1,2,2,2-

Pentafluoro-

n-

[(pentafluoro ethyl)sulfonyl

]

ethane-

sulfonamide

2-(2-

Methoxyetho

xy)ethyl

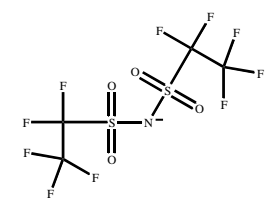

A1

sulfate

Bis[(trifluoro

methyl)sulfo

nyl]

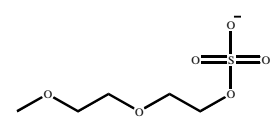

imide

Bromide

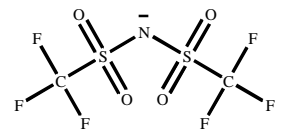

A3

Bromide

\section{REFERENCES}

1. Abdulagatov, I. M., A. Tekin, J. Safarov, and E. Hassel (2008a). Densities and excess, apparent, and partial molar volumes of binary mixtures of $\mathrm{BMIMBF}_{4}+$ ethanol as a function of temperature, pressure, and concentration. Int. J. Thermophys., Vol. 29, 505-533.

2. Abdulagatov, I. M., A. Tekin, J. Safarov, A. Shahverdiyev, and E. Hassel (2008b). High-pressure densities and derived volumetric properties (excess, apparent, and partial molar volumes) 

Propanol) using Artificial Neural Network

of binary mixtures of \{methanol (1) + [BMIM] $\left[\mathrm{BF}_{4}\right]$ (2)\}. J. Chem. Thermodyn., Vol. 40, 1386-1401.

3. Abdulagatov, I. M., J. Safarov, T. Guliyev, A. Shahverdiyev, and E. Hassel (2009). High temperature and high pressure volumetric properties of (methanolY[BMIMY][OcSOZ mixtures. Phys. Chem. Liq., Vol. 47, 934.

4. Andreatta, A. E., A. Arce, E. Rodil, and A. Soto (2009a). Physical properties of binary and ternary mixtures of ethyl acetate, ethanol, and 1-octyl-3-methylimidazolium

bis(trifluoromethylsulfonyl)imide at 298.15 K. J. Chem. Eng. Data, Vol. 54, 1022.

5. Andreatta, A. E., A. Arce, E. Rodil, and A. Soto (2009b). Physical and excess properties of (methyl acetate + methanol + 1-octyl-3-methylimidazolium

bis(trifluoromethylsulfonyl)imide) and its binary mixtures at $T=298.15 \mathrm{~K}$ and atmospheric pressure. J. Chem. Thermodyn., Vol. 41, 1317-1323.

6. Andreatta, A. E., A. Arce, E. Rodil, and A. Soto (2010). Physico-chemical properties of binary and ternary mixtures of ethyl acetate + ethanol + 1-butyl-3-methyl-imidazolium bis(trifluoromethylsulfonyl)imide at $298.15 \mathrm{~K}$ and atmospheric pressure. J. Solution Chem., Vol. 39, 371-383.

7. Arce, A., H. Rodriguez, and A. Soto (2006a). Effect of anion fluorination in 1-ethyl-3-methylimidazolium as solvent for the liquid extraction of ethanol from ethyl tert-butyl ether. Fluid Phase Equilib., Vol. 242, 164-168.
8. Arce, A., E. Rodil, and A. Soto (2006b). Volumetric and viscosity study for the mixtures of 2-ethoxy-2methylpropane, ethanol, and 1-ethyl3-methylimidazolium ethyl sulfate ionic liquid. J. Chem. Eng. Data, Vol. 51, 1453-1457.

9. Bhujrajh, P. and N. Deenadayalu (2007). Liquid densities and excess molar volumes for binary systems (ionic liquids + methanol or water) at 298.15 , 303.15 and $313.15 \mathrm{~K}$, and at atmospheric pressure. J. Solution Chem., Vol. 36, 631-642.

10. Calvar, N., B. Gonzales, E. Gomez, and A. Dominguez (2006). Vapor-liquid equilibria for the ternary system ethanol + water +1 -butyl-3methylimidazolium chloride and the corresponding binary systems at 101.3 kPa. J. Chem. Eng. Data, Vol. 51, 21782181.

11. Deenadayalu, N. and P. Bhujrajh (2008). Density, speed of sound, and derived thermodynamic properties of ionic liquids $\quad[E M I M]+[B E T I]-$ or $\left([\mathrm{EMIM}]+\left[\mathrm{CH}_{3}\left(\mathrm{OCH}_{2} \mathrm{CH}_{2}\right)_{2} \mathrm{OSO}_{3}\right]-\quad+\right.$ methanol or + acetone $)$ at $T=(298.15$ or 303.15 or 313.15$)$ K. J. Chem. Eng. Data, Vol. 53, 1098-1102.

12. Diedenhofen, M. and A. Klamt (2010). COSMO-RS as a tool for property prediction of IL mixtures- A review. Fluid Phase Equilib., Vol. 294, 31-38.

13. Domanska, U., A. Pobudkowska, and A. Wisniewska (2006). Solubility and excess molar properties of 1,3dimethylimidazolium methylsulfate, or 1-butyl-3-methylimidazolium methylsulfate, or 1-butyl-3methylimidazolium octylsulfate ionic 
liquids with $\mathrm{n}$-alkanes and alcohols: analysis in terms of the PFP and FBT models. J. Solution Chem., Vol. 35, 311334.

14. Domanska, U. and M. Laskowska (2008). Phase equilibria and volumetric properties of (1-ethyl-3methylimidazolium ethylsulfate + alcohol or water) binary systems. J. Solution Chem., Vol. 37, 1271-1287.

15. Domanska, U. and M. Laskowska (2009). Temperature and composition dependence of the density and viscosity of binary mixtures of 11 -butyl3-methylimidazolium thiocyanate +1 alcohols\}. J. Chem. Eng. Data, Vol. 54, 2113-2119.

16. Garcia-Miaja, G., J. Troncoso, and L. Romani (2008). Excess properties for binary systems ionic liquid + ethanol: Experimental results and theoretical description using the ERAS model. Fluid Phase Equilib., Vol. 274, 59-67.

17. Gardas, R. L. and J. A. P. Coutinho (2008). A group contribution method for the viscosity estimation of ionic liquids. Fluid Phase Equilib., Vol. 266, 195-201.

18. Gardas, R. L. and J. A. P. Coutinho (2009). Group contribution methods for the prediction of thermophysical and transport properties of ionic liquids. AlChE J., Vol. 55, 1274-1290.

19. Giro, F. M., F. A. Gonzales, and A. G. M. Ferreira., I. M. A. Fonseca (2003). Viscosity and density data of the system water $+\mathrm{n}$-pentyl acetate + methanol: calculations with a modified Redlich-Kwong-Soave equation of state. Fluid Phase Equilib., Vol. 204, 217.
20. Goldon, A., K. Dabrowska, and T. Hofman (2007). Densities and excess volumes of the 1,3dimethylimidazolium methylsulfate + methanol system at temperatures from (313.15 to 333.15) $\mathrm{K}$ and pressures from (0.1 to 25) MPa. J. Chem. Eng. Data, Vol. 52, 1830-1837.

21. Gomez, E., N. Calvar, I. Dominguez, and A. Dominguez (2006a). Physical properties of the ternary mixture ethanol + water + 1-hexyl-3methylimidazolium chloride at 298.15K. Phys. Chem. Liq., Vol. 44, 409417.

22. Gomez, E., B. Gonzalez, N. Calvar, E. Tojo, and A. Dominguez (2006b). Physical properties of pure 1-ethyl-3methylimidazolium ethylsulfate and its binary mixtures with ethanol and water at several temperatures. J. Chem. Eng. Data, Vol. 51, 2096-2102.

23. Gomez, E., B. Gonzalez, N. Calvar, and A. Dominguez (2008). Excess molar properties of ternary system (ethanol + water + 1,3-dimethylimidazolium methyl sulfate) and its binary mixtures at several temperatures. J. Chem. Thermodyn., Vol. 40, 1208-1216.

24. Gonzalez, E. J., L. Alonso, and A. Dominguez (2006). Physical properties of binary mixtures of the ionic liquid 1methyl-3-octylimidazolium chloride with methanol, ethanol, and 1propanol at $T=(298.15,313.15$, and 328.15) $\mathrm{K}$ and at $\mathrm{P}$ ) $0.1 \mathrm{MPa}$. J. Chem. Eng. Data, Vol. 51, 1446-1452.

25. Gonzalez, E. J., B. Gonzales, N. Calvar, and A. Dominguez (2007). Physical properties of binary mixtures of the ionic liquid 1-ethyl-3- 
48 Prediction of Density of Binary Mixtures of Ionic Liquids with Alcohols (Methanol/Ethanol/1Propanol) using Artificial Neural Network

methylimidazolium ethyl sulfate with several alcohols at $T=(298.15,313.15$, and 328.15) $\mathrm{K}$ and atmospheric pressure. J. Chem. Eng. Data, Vol. 52, 1641-1648.

26. Gonzalez, B., N. Calvar, E. Gomez, and A. Dominguez (2008). Physical properties of the ternary system (ethanol + water +1 -butyl-3methylimidazolium methylsulphate) and its binary mixtures at several temperatures. J. Chem. Thermodyn., Vol. 40, 1274-1281.

27. Gonzalez, B., N. Calvar, E. Gomez, I. Dominguez, and A. Dominguez (2009). Synthesis and physical properties of 1ethylpyridinium ethylsulfate and its binary mixtures with ethanol and 1propanol at several temperatures. J. Chem. Eng. Data, Vol. 54, 1353-1358.

28. Han, C., S. Xia, P. Ma, and F. Zeng (2009). Densities of ionic liquid $[\mathrm{BMIM}]\left[\mathrm{BF}_{4}\right]$ + ethanol, + benzene, and + acetonitrile at different temperature and pressure. J. Chem. Eng. Data, Vol. 54, 2971-2977.

29. Heintz, A., D. Klasen, and J. K. Lehmann (2002). Excess molar volumes and viscosities of binary mixtures of methanol and the ionic liquid 4methyl-n-butylpyridinium tetrafluoroborate at 25, 40, and 50 deg C. J. Solution Chem., Vol. 31, 467-476.

30. Hofman, T., A. Goldon, A. Nevines, and T. M. Letcher (2008). Densities, excess volumes, isobaric expansivity, and isothermal compressibility of the (1ethyl-3-methylimidazolium ethylsulfate + methanol) system at temperatures (283.15 to 333.15$) \mathrm{K}$ and pressures from (0.1 to 35) MPa. J. Chem.
Thermodyn., Vol. 40, 580-591.

31. Huo, Y., S. Xia, and P. Ma (2007). Densities of ionic liquids, 1-butyl-3methylimidazolium

hexafluorophosphate and 1-butyl-3methylimidazolium tetrafluoroborate, with benzene, acetonitrile, and 1propanol at $T=(293.15$ to 343.15$) \mathrm{K}$. J. Chem. Eng. Data, Vol. 52, 2077-2082.

32. Iglesias-Otero, M. A., J. Troncoso, and E. Carballo (2007). Density and refractive index for binary systems of the ionic liquid $[\mathrm{Bmim}]\left[\mathrm{BF}_{4}\right]$ with methanol, 1,3-dichloropropane, and dimethyl carbonate. J. Solution Chem., Vol. 36, 1219-1230.

33. Iglesias-Otero, M. A., J. Troncoso, E. Carballo, and L. Romani (2008a). Density and refractive index in mixtures of ionic liquids and organic solvents: Correlations and predictions. J. Chem. Thermodyn., Vol. 40, 949-956.

34. Iglesias-Otero, M. A., J. Troncoso, E. Carballo, and L. Romani (2008b). Densities and excess enthalpies for ionic liquids + ethanol or + nitromethane. J. Chem. Eng. Data, Vol. 53, 1298-1301.

35. Kurnia, A., Wilfred, C.D, and T. Murugesan, 2009. Thermophysical properties of hydroxyl ammonium ionic liquids. J. Chem. Thermodyn., Vol. 41, 517-521.

36. Liu, W., L. Cheng, Y. Zhang, H. Wang, and M. Yu (2008). The physical properties of aqueous solution of room-temperature ionic liquids based on imidazolium: database and evaluation. J. Mol. Liq., Vol. 140, 68-72.

37. Matkowska, D., A. Golden, and T.Hofman (2010). Densities, excess 
volumes, isobaric expansivities, and isothermal compressibilities of the 1ethyl-3-methylimidazolium ethylsulfate + ethanol system at temperatures (283.15 to 343.15) $\mathrm{K}$ and pressures from (0.1 to 35) MPa. J. Chem. Eng. Data, Vol. 55, 685-693.

38. Mokhtarani, B., M. M. Mojtahedi, H. R. Mortaheb, M. Mafi, F. Yazdani, and F. Sadeghian (2008). Densities, refractive indices, and viscosities of the ionic liquids 1-methyl-3-octylimidazolium tetrafluoroborate and 1-methyl-3butylimidazolium perchlorate and their binary mixtures with ethanol at several temperatures. J. Chem. Eng. Data, Vol. 53, 677-682.

39. Mokhtarani, B., A. Sharifi, H. R. Mortaheb, M. Mirzaei, M. Mafi, and F. Sadeghian (2009). Density and viscosity of 1-butyl-3methylimidazolium nitrate with ethanol, 1-propanol, or 1-butanol at several temperatures. J. Chem. Thermodyn., Vol. 41, 1432-1438.

40. Orchilles, A. V., V. Gonzalez-Alfaro, P. J. Miguel, E. Vercher, and A. MartinezAndreu (2006). Volumetric properties of binary mixtures of ionic liquid 1butyl-3-methylimidazolium octylsulfate with water or propanol in the temperature range of $278.15 \mathrm{~K}$ to 328.15 K. J. Chem. Thermodyn., Vol. 38, 1124-1129.

41. Ortega. J., R. Vreekamp, E. Penco, and E. Marrero (2008). Mixing thermodynamic properties of 1-butyl4-methylpyridinium tetrafluoroborate $\left[\mathrm{b}_{4} \mathrm{mpy}\right]\left[\mathrm{BF}_{4}\right]$ with water and with an alkan-1ol (methanol to pentanol). J. Chem. Thermodyn., Vol. 40, 1087-1094.
42. Pereiro, A. B. and A. Rodriguez (2007). Study on the phase behaviour and thermodynamic properties of ionic liquids containing imidazolium cation with ethanol at several temperatures. J. Chem. Thermodyn., Vol. 39, 978-989.

43. Rilo, E., J. Pico, S. Garcia-Garabal, L. M. Varela, and O. Cabeza (2009). Density and surface tension in binary mixtures

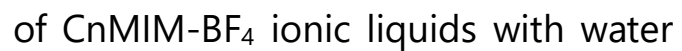
and ethanol. Fluid Phase Equilib., Vol. 285, 83-89.

44. Shekaari, H. and M. T. Zafarani-Moattar (2008). Volumetric properties of the ionic liquid, 1-butyl-3methylimidazolium tetrafluoroborate, in organic solvents at $T=298.15 \mathrm{~K}$. Int . J. Thermophys., Vol. 29, 534-545.

45. Soriano, A. N., A. Agapito, L. J. L. Lagumbay, A. R. Caparanga, and MH.Li (2010).A simple approach to predict molar heat capacity of ionic liquids using group-additivity method. J. Taiwan Inst. Chem. Engrs., Vol. 41, 307-314.

46. Soriano A. N., M. K. L. Gimena, R. R. C. Rivera, M. A. M. Garcia, and R. R. Tan, (2014). Prediction of density and refractive index of binary aqueous ionic liquid solutions using artificial neural network. PIChE J., Vol. 15, 72-91.

47. Stoppa, A., J. Hunger, and R. Buchner (2009). Conductivities of binary mixtures of ionic liquids with polar solvents. J. Chem. Eng. Data, Vol. 54, 472-479.

48. Valderrama, J.O., A. Toro, and R. E. Rojas (2011). Prediction of the heat capacity of ionic liquids using the mass connectivity index and a group contribution method.. J. Chem. 
50 Prediction of Density of Binary Mixtures of Ionic Liquids with Alcohols (Methanol/Ethanol/1Propanol) using Artificial Neural Network

Thermodyn., Vol. 43, 1068-1073.

49. Vercher, E., A. V. Orchilles, P. J. Miguel, and A. Martinez-Andreu (2007). Volumetric and ultrasonic studies of 1ethyl-3-methylimidazolium trifluoromethanesulfonate ionic liquid with methanol, ethanol, 1-propanol, and water at several temperatures. J. Chem. Eng. Data, Vol. 52, 1468-1482.

50. Viswanadhan V. N., A. K. Ghose, G. R. Revankar, and R. K. Robins (1989). Atomic physicochemical parameters for three dimensional structure directed quantitative structure-activity relationships. 4. additional parameters for hydrophobic and dispersive interactions and their application for an automated superposition of certain naturally occurring nucleoside antibiotics. J. Chem. Inf. Comput. Sci., Vol. 29, 163-172.

51. Wandschneider, A., J. K. Lehmann, and A. Heintz (2008). Surface tension and density of pure ionic liquids and some binary mixtures with 1-propanol and 1-butanol. J. Chem. Eng. Data, Vol. 53, 596-599.

52. Yang, Q., H. Zhang, B. Su, Y. Yang, Q. Ren, and H. Xing (2010). Volumetric properties of binary mixtures of 1 butyl-3-methylimidazolium chloride + water or hydrophilic solvents at different temperatures. J. Chem. Eng. Data, Vol. 55, 1745-1749.
53. Zafarani-Moattar, M. T. and H. Shekaari (2005a). Apparent molar volume and isentropic compressibility of ionic liquid 1-butyl-3-methylimidazolium bromide in water, ethanol, and ethanol at $\mathrm{T}=(298.15$ to 318.15$) \mathrm{K}$. J. Chem. Thermodyn., Vol. 37, 1029-1035.

54. Zafarani-Moattar, M. T. and H. Shekaari (2005b). Volumetric and speed of sound of ionic liquid, 1-butyl-3methylimidazolium

hexafluorophosphate with acetonitrile and methanol at $T=(298.15$ to 318.15$)$ K. J. Chem. Eng. Data, Vol. 50, 16941699.

55. Zafarani-Moattar, M. T. and H. Shekaari (2006a). Volumetric and compressibility behaviour of ionic liquid, 1-n-butyl-3-methylimidazolium hexafluorophosphate and tetrabutylammonium hexafluorophosphate in organic solvents at $\mathrm{T}=298.15 \mathrm{~K}$. J. Chem. Thermodyn., Vol. 38, 624-633.

56. Zafarani-Moattar, M. T. and H. Shekaari (2006b). Application of Prigogine Flory Patterson theory to excess molar volume and speed of sound of $1-n-$ butyl-3-methylimidazolium hexafluorophosphate or 1-n-butyl-3methylimidazolium tetrafluoroborate in methanol and acetonitrile. J. Chem. Thermodyn., Vol. 38, 1377-1384. 